\title{
PSICOLOGIA NA VISÃO DE PSICÓLOGOS E PSIQUIATRAS BRASILEIROS DAS PRIMEIRAS DEECADAS DO SÉCULO XX
}

\author{
Marina Massimi*
}

\section{RESUMO}

O trabalho relata alguns aspectos significativos da discussão acerca dos modelos de Psicologia científica que se delineou em vários artigos publicados em periódicos científicos brasileiros nas primeiras décadas do século $\mathrm{XX}$. Nesses, médicos, filósofos e psicólogos discutem os objetos, os métodos, os objetivos e a utilidade da Psicologia científica, tendo em vista os desenvolvimentos das mais importantes propostas teóricas, como a Psicanálise, o Behaviorismo, a Teoria da Forma, e confrontando-as com os desafios e as problemáticas da realidade sócio-cultural brasileira. A cientificidade da Psicologia é discutida tendo como referencial modelos mais gerais de ciência.

\section{INTRODUÇÃO}

Nas primeiras quatro décadas do século $\mathrm{XX}$, trava-se entre os psicólogos e psiquiatras brasileiros um interessante debate acerca da definição da Psicologia e dos objetos e métodos dessa disciplina. $O$ debate ocupa várias páginas de revistas médico-científica da época sendo o reflexo, em muitos casos, de uma preocupação sistemática e didática para com a Psicologia. Além disso existe o esforço de justificar e promover a institucionalização dessa disciplina visando sua utilidade social.

A discussão assume características peculiares conforme às diferentes regiões onde se desenvolve mas em geral aparece dominate a influência cultural do Positivismo, que constitui-se na maioria dos casos como o

Professora Doutora do Depto de Psicologia e Educação - FFCLRP-USP - Campus de Ribeirão Preto. 
back-ground de referência ou o principal alvo crítico necessário para definir e situar a ciência dos fenômenos psíquicos.

\section{DEFINIÇÓES DE PSICOLOGIA}

Em particular, vários autores empregam a definição contiana de Psicologia como Fisiologia Mental - definição introduzida no Brasil pelo médico e filósofo paulista Luis Pereira Barreto (1874) e que permite uma localização dessa nova ciência no ãmbito dos estudos médicos -. O médico paulista Pedro de Alcântara - por exemplo - afirma com toda clareza: 'Por sua natureza verdadeira physiologia das funções mentaes - a psychologia experimental ha de encontrar sempre na medicina o ambiente melhor ao seu desenvolvimento'. (1924, p. 4).

De maneira semelhante, em Salvador, Carlos Ribeiro, professor de Psicologia no Curso superior de Administração e Finanças, declara que 'toda a estrutura da Psicologia repousa na Fisiologia' (1934, p. 330). O neuro-psiquiatra carióca Nilton Campos refere-se a Comte em uma conferência realizada junto ao Serviço de Neuropsiquiatria da Assistência Municipal do Rio de Janeiro (1935).

Medeiros afirma que o objeto investigado pela Psicologia é a 'relação inegável que ha entre certos estados de consciência, ou melhor de certos phenomenos psychicos, e estados physiologicos' (1908, p. 40).

Portanto, o referencial teórico de vários autores parece ser uma visão positivista da ciência. A ciência assim concebida proporcionaria ao homem a possibilidade de 'assegurar alguma felicidade no plano da vida terrena' (Campos, 1935, p. 64) permitindo 'aplicaçōes práticas úteis ao homem e a sociedade'. (Campos, 1935, 63).

Nos textos analisados, a matriz positivista faz-se evidente em alguns aspectos tais como a recusa da Metafisica, a afirmação da Psicologia como ciência positiva, factual, e capaz de desvendar as leis fundamentais dos fenômenos, a declaração de que o método experimental é a única modalidade científica de conhecimento. 'Não compreendo Psicologia, que não seja experimental', afirma Carlos Ribeiro (1932, p. 327). De maneira analoga, escreve Mauricio de Medeiros criticando a divisão tradicional de Psicologia Racional e Experimental: ‘Ora, nos acreditamos que a bem dizer não há duas psychologias - 
uma experimental e outra não -. A psychologia e uma só, que é a psychologia científica' (1908, p. 40).

O conceito de Psicologia como uma ciência que se coloca entre Biologia e Sociologia, a declaração da neutralidade do cientista frente d̀s questões éticas e culturais, são também heranças dessa postura filosófica presentes nos psicólogos brasileiros da época.

$E$ interessante, nesse sentido, citar uma afirmação feita por Nilton Campos, numa conferência pronunciada, em qualidade de paraninfo, para os estudantes de Enfermagem Social: ' $O$ homem de sciencia deve permanecer neutro diante da esphera dos valores. E da própria essência do espírito scientifico ficar indiferente as categorias ethicas' $(1835$, p. 223$)$. E, nesse sentido, continua: 'Em minhas modestas aulas, nunca vos defini o que era a pessoa humana, sob o ponto de vista finalístico de sua significação no plano dos valores morais. Permaneci submisso ao postulado da indiferença que todo cientista puro deve atender dentro do dominio da pesquisa scientifica. '(Idem p. 224,). Assim, apenas na lição final do curso. Nilton Campos lembra aos seus alunos que 'o homem é um anjo, é um animal, é um monstro'. (1935, p. 224).

Em suma, no plano da Psicologia, a postura da neutralidade significativa eliminar do domínio científico a discussão acerca da visão de homem, pois isso implicaria - na ótica de Campos - uma volta à Metafísica: 'deixou a psychologia de ser metaphysico estudo do psychismo humano, encarando o homem como ser ideal, para tornar-se um instrumento scientifico de analyse concreta da vida psychica do homem, considerado como entidade real psycho-biologico na escala dos seres vivos, que se congregam em sociedades nos seus graus de desenvolvimento diverso' (1935, p. 5). Dessa forma, a Psicologia cessa de ser 'devaneio literário' torna-se poderoso instrumento de acção scientifica' (idem, p. 6).

A enfase nas consequências práticas do estudo científico do homem - no plano educacional, social e econômico - é particularmente evidente na postura do já citado médico paulista Pedro de Alcântara (1924). A preocupação de Alcântara - mais do que a discussão teórica acerca dos fundamentos e da definição de Psicologia - é a de apontar as aplicações práticas e socialmente úteis da Psicologia experimental, justificando a necessidade da introdução dessa disciplina nos estudos da Faculdade de Medicina de São Paulo.

Partindo da constatação do desleixo em que a Psicologia é deixada na cultura brasileira - pois a educação nesse contexto privilegia o conhecimento 
dos fenômenos objetivos e não o do mundo subjetivo - Alcântara enfatiza a vitalidade de nova Psicologia Experimental e a utilidade de suas aplicações nas áreas da Pedagogia, da organização industrial do trabalho, do regime penitenciário e da Psiquiatria.

No que diz respeito ao exame psíquico da criança no meio escolar os métodos da Psicologia Experimental possibilitam a 'classificação rigorosa' dos níveis de desenvolvimento e das diferenças individuais.

$\mathrm{Na}$ organização industrial, a 'psychologia experimental' é uma poderosa auxiliar do projeto taylorista, 'essa formidável revolução operada no mundo technico e que consiste no maior aproveitamento do operário graças à sua (da Psicologia experimental: ndr) aplicação ao mister a que melhor se presta sua constituição organica e mental' $(1923$, p. 3).

Quanto ao regime nas prisōes, a Psicologia Experimental, apontando a existência do determinismo psíquico, possibilita a modificação do comportamento dos presos pela 'dissecção mental do criminoso, afim de se ver onde está o desvio que o levou ao crime, e corrigi-lo’ (1923, p. 4).

Segundo Alcântara, a Psicologia Experimental é especialmente necessária à Psiquiatria, pois uma 'Psychiatria sem Psychologia é synonimo de clínica sem Physiologia' (idem, p. 4). Com efeito, 'como conhecer uma função perturbada se não a conhecemos normal?' (ibidem). Nessa perspectiva, a psicoterapia é considerada como um 'processo de reeducação' (ibidem). É interessante observar que Alcântara considera a 'psychoanalyse uma das mais brilhantes conquistas da psychologia experimental' (ibidem) - o que demonstra 0 escasso rigor teórico e a preocupação marcadamente pragmatista de sua posição.

O valor da contribuição desse autor está justamente na proposta de uma institucionalização da Psicologia enquanto disciplina acadêmica e técnica de intervenção na sociedade. A esse respeito, há, na conclusão do artigo, uma recomendação significativa de teor nacionalista que transcrevemos a seguir. $O$ autor se refere à necessidade da formação de psicólogo profissional 'A formação desses peritos há de ser feita em casa, para que impeçamos a tempo a importação de peritos estrangeiros, nem sempre bastante competentes, algumas vezes charlatães e sempre muito dispendiosos' (idem, p. 4).

Todavia, não se deve pensar que a consciência dos psicólogos brasileiros da época com relação à sua área de estudo se limitará apenas ao aspecto prático e técnico. Na realidade, sobretudo no contexto cultural do Rio de 
Janeiro, trava-se, nas décadas dos anos vinte e trinta, um debate bastante interessante sobre a definição, os objetos e os métodos da Psicologia.

Da mesma forma, nas páginas de uma revista mineira de 1940 ('Arquivos de Neurologia e Psiquiatria'), pode-se encontrar o relato de uma aula inaugural ministrada pelo professor Galba Veloso na abertura do curso pré-médico do Colégio Universitário que apresenta uma rica exposição histórica do desenvolvimento da Psicologia e um panorama das tendências da Psicologia contemporânea.

Surpreende, nesse texto, a consciência histórico-crítica do autor, que em várias ocasiōes evidencia as matrizes culturais das diversas posturas teóricas, pois toda escola não é apenas 'uma corrente isolada, que tenha surgido, de improviso, nesse oceano de competições doutrinárias' (1940, p. 131), mas é o produto de um longo processo histórico, cujas origens remontam em muitos casos à filosofia grega clássica. De acordo semelhante, a origem da Psicologia Experimental não é encarada como a criação individual e genial de Wundt, mas como a convergência de 'influência inumeras e complexas, que atuando como um sistema de forças, encaminharam o grande sábio germânico para as diretrizes que o imortalizaram' (idem, p. 8). A genese histórica das teorias é evidente também no caso da doutrina psicanalítica, que 'não surgiu do cérebro do seu autor como um deus ex machina, não brotou do nada, do improviso, já com todo um sistema de doutrina, completo e acabado. É filha de experiência, e o primeiro material em que se plasmou, foi um material patológico...'(1940, p. 11). Além disso, havia a tendência, 'já então, na medicina psiquiátrica, de dar um sentido aos sintomas das moléstias nervosas, bem como ao delírio dos alienados' (1940, p. 11).

Quanto ao panorama da Psicologia contemporânea, Galba Veloso assinala a existência de duas atitudes 'uma, que faz da vida do espírito algo sui generis, e para cujo estudo são falhos e improprios os métodos das ciências naturais; outra, que justamente considera a psicologia como um capítulo da biologia, tendo como método os métodos da fisiologia'. (idem, p. 13). Segundo o autor, na época predomina a visão dos 'biologistas', cujo representante mais significativo é Watson. Quanto aos portavózes da primeira concepção, Veloso cita E. Husserl, W. James, H. Bergson, F. Brentano e S. Freud.

Uma análise semelhante acerca da situação dicotômica da Psicologia moderna encontra-se nos artigos de outros autores. Carlos Ribeiro, por exemplo, afirma haver duas doutrinas 'extremistas' em Psicologia: os 
'partidários de uma extremada Psicologia objetiva' e outros 'reacionários do neo-espiritualismo' (1932, p. 325).

Um nível mais sofisticado e aprofundado de investigação da mesma questão encontra-se em artigos de alguns psicólogos que atuaram no Rio de Janeiro: Maurício de Medeiros, Waclaw Radecki, Eurialo Cannabrava e Jayme Grabois.

Todos esses concordam acerca da dificuldade - ou até da impossibilidade - de encontrar uma definição unívoca de Psicologia e de seu objeto. ' $E$ interessante ver que - observa a respeito Maurício de Medeiros - sendo esse o ponto de partida naturalmente indicado para essa ciência, seja sobre ela que mais controversias surjam e que os autores mais confusos se tornem' (1908, p. 23).

Essa dificuldade é comprovada também considerando o percurso histórico da Psicologia que evoluiu de disciplina filosófica a ciência. Segundo Radecki, o caráter dinâmico-evolutivo de todo conhecimento humano, implica na necessidade de relativizar, do ponto de vista histórico, a definição de uma área do saber numa determinada época, de maneira que esta definição não venha no futuro a restringir demasiado o campo de investigação. No que se refere à nossa área de estudos 'por exemplo - 'uma definição da psychologia como uma ciência natural particular é uma definição justa para a nossa época. Esta definição não pode subentender a direção do desenvolvimento futuro da evolução dos problemas psicológicos (1924, p. 278).

Jayme Grabois (1934), professor do Instituto de Psicologia da Universidade do Rio de Janeiro, alerta que todo caminho de aperfeiçoamento de uma ciência envolve o desaparecimento das doutrinas entre si conflitantes, possibilitando a unificação dos conceitos primários e dos postulados. $\mathrm{Na}$ Psicologia, pelo contrário, permanecem e proliferam cada vez mais orientações diferentes. De modo geral, essa disciplina apresenta uma falta de unidade que implica também na definição de diferentes objetos e métodos.

Segundo Medeiros e Radecki, essa situação crítica é devida ao permanecer - na Psicologia - de pontos de vista filosóficos externos e conflitantes, que devem ser eliminados. Em vez disso importa determinar os objetos e os métodos de estudo de disciplina, pois isso possibilitará um real progresso científico, da mesma forma que ocorre em outras áreas (por exemplo, a química). 


\section{OBJETOS DA PSICOLOGIA}

Quanto aos objetos, uma vez que a Psicologia científica rejeitou o conceito de alma enquanto entidade filosófica e hipotética, os autores concordam em defini-los em termos de fatos, ou fenômenos.

Na linguagem da Psicologia da época, utiliza-se normalmente a categoria de fenômenos psíquicos mas é necessário explicitar o que se entende com tal expressão: Radecki considera inadequado identificar o campo do psiquismo com o da consciência, pois esse ingloba também os fenômenos psíquicos inconscientes ou 'sub-conscientes'. Ao mesmo tempo, porém seria insatisfatória uma definição dos ditos fenômenos em termos de fenômenos biológicos vitais não redutíveis ao nível da física e da química. Parece-lhe mais correto considerar os mesmos sínteses subjetivas impostas pelo ser vivo a determinadas relações entre processos físicos e químicos. Em outras palavras, os fatos psíquicos seriam concomitantes subjetivos e sintéticos dos fenômenos vitais objetivos.

Radecki propõe um exemplo significativo para explicar esta definição. $O$ fenômeno da visão possue um aspecto físico e químico - no que diz respeito à sua natureza fisiológica - e um correlato subjetivo correspondente à experiência do sujeito que vê e que se expressa na afirmação 'eu vejo': 'Se se chegar algum dia a esclarecer as milhares de reacções physicas e chimicas, que entram em um processo de visão e de audição - o homem que vê dirá sempre 'eu vejo'. De tal maneira, este homem vai atribuir a uma série de reacç̧ões physicas e chimicas (mesmo explicadas e esclarecidas perfeitamente pela physica e pela chimica) um caracter de synthese subjectiva, que generaliza em um phenomeno subjectivo todo o conjunto das reacções, que a physica e a chimica deverão explicar e enumerar em milhares de termos' (1924, p. 280).

Evidentemente, todo estado subjetivo deve ser sempre investigado juntamente com seu correlato objetivo e, se for possível, devem-se determinar as relações causais - ou leis que ligam as duas ordens de fenômenos.

\section{MÉTODOS DA PSICOLOGIA}

Quanto aos métodos - seja Medeiros seja Radecki - preocupam-se em fornecer uma descrição cuidadosa e detalhada das diversas opções possíveis. 
Os dois autores concordam acerca do fato de que todo método deve responder aos objetivos de descrição e de explicação causal dos fenômenos. Os tipos de métodos indicados são: a observação (interna e externa, normal e patológica, do comportamento humano ou animal) e a experimentação em laboratório (normal e patológica).

Ambos os autores procuram diferenciar esses métodos da auto-observação tradicionalmente utilizada pelo senso comum. $O$ psicólogo experimental, ao analisar um relato colhido por introspeção, está interessado na descrição que o sujeito observado fornece acerca do próprio estado subjetivo mas não na interpretação que ele dá do mesmo. A interpretação, ou explicação causal, cabe ao psicólogo. A esse respeito cabe citar a crítica que Medeiros formula acerca dos questionários como métodos de investigação psicológica. Embora 'os americanos levem a palma' essas modalidades de 'enquêtes escriptas' baseadas na distribuição 'entre vários indivíduos normais ou não, de um questionário para cuja resposta estão muitas vezes pouco preparados' (1908, p. 30, nota de rodapé), Medeiros afirma que esse método reduz a observação à auto-observação, 'fiando-se o psychologo no que lhe responde o observado por um questionário, cujas perguntas são fixas e invariáveis para todos'. (ibidem)

Embora a introspeção seja admitida entre os métodos científicos da Psicologia, são assinalados seus limites entre os quais a estreiteza do campo da consciência do sujeito, que não engloba os fenômenos inconscientes; os limites e as distorções da memória que inviabilizam os relatos de estados subjetivos passados: a impossibilidade de observação direta dos estados afetivos - pois cada tentativa de autoanálise nesse nível modifica e dissocia os mesmos.

No que diz respeito à observação do comportamento animal ou patológico, parece interessante a postura de Medeiros, pois focaliza as diferenças entre Psiquiatria e Psicopatologia, no nível metodológico. $O$ 'alienista' (ou médico-psiquiatra) estuda - através da observação clinica - as doenças mentais estabelecendo tipos clínicos e analisando casos enquanto que o psicopatologista observa em cada fenômeno anormal os elementos que permitem o estudo de uma determinada função psíquica. ' $O$ que o psycho-pathologo faz é estudar no doente aquilo que lhe convém. Se por exemplo nos fazemos um estudo sobre a alegria, ou sobre a colera, tomamos a pressão arterial, medimos a força muscular, a altura da respiração, etc... numa série de doentes que desfilam a nossos olhos 'paralyticos geraes, maniácos, etc... pouco importando os seus delírios, apenas nos importando saber se, no momenţo em que fazemos a nossa experiência, elles estão alegres, ou coléricos' (1908, p. 43). 
São muito enfatizadas as vantagens da experimentação em laboratório, definida como o 'estudo meticuloso e detalhado das funcções psychicas, feito com o auxílio de aparelhos registradores, que assinalam as suas manifestações de um modo objectivo' (Medeiros, 1908, p. 39). Radecki sobretudo aprofunda esse aspecto alertando os leitores acerca da possibilidade de se estudarem apenas fenômenos simples no laboratório pois, no caso dos fenômenos psiquicos mais complexos, as diversas funções agem em conjunto sendo inviável isolar um elemento do contexto global ao qual pertence, a não ser reduzindo teoricamente o problema estudado. Os processos criativos e o pensamento - por exemplo - não podem ser investigados em laboratório.

A seguir, Radecki descreve os equipamentos de um laboratório de Psicologia que devem ser de três tipos: aparelhos para a produção de condiçōes excitantes; relógios (cronoscópios) para medição dos tempos de reação; aparelhos fisiológicos para detectar os concomitantes orgânicos dos processos psíquicos.

E interessante observar que a concepção de laboratório de Radecki não é restrita ao laboratório de pesquisa experimental em senso estrito mas abrange também aspectos de aplicação imediata - o que autor define como 'psicotécnica experimental'. Nesse sentido, o laboratório pode proporcionar serviços para o exame psicológico das atitudes profissionais, para a elaboração de técnicas de organização do trabalho produtivo e até de táticas militares.

Nesse sentido, recomenda-se a instalação de laboratórios de Psicologia Experimental nas escolas, nos hospícios de alienados e nas prisões.

\section{OBJETIVOS DA PSICOLOGIA}

A Psicologia se configura então não apenas como ciência básica mas também como meio de higiene social: por isso, toda instituição social (prisão, escola, hospital) pode ser considerada como um potencial laboratório e o campo de abrangência dos estudos da Psicologia torna-se a sociedade inteira e o homem como um todo: 'Sim - a Psicologia é, de fato, imperialista. Tudo avassala': afirmava Carlos Ribeiro (1932, p. 324).

Resta ver como essa pretenção de totalidade se concilia com a declaração de neutralidade da Psicologia quanto aos valores éticos, culturais e 
políticos, neutralidade proclamada pelos psicólogos da época, como vimos anteriormente. Tal neutralidade é declarada também pelo próprio Radecki ao apresentar um projeto de sistematização teórica da Psicologia, para elaborar o qual - ele diz - 'baseei exclusivamente nas premissas psychologicas, isto é, na investigação minuciosa detalhada das relações correlativas de todos os fenômenos psychicos' (1924, p. 528).

Aparece uma intrinseca contradição nessas ạirmações ou talvez o desvelar-se de um back-ground ideológico inconfessado - se é verdade - como se queixa Jayme Grabois - que entre os motivos da crise atual da Psicologia há 'a falta de sinceridade, isto é, a aceitação implicita de certos princípios e pontos de vista, em flagrante contradição com os princípios e pontos de vista formalmente manifestados' (1934, p. 277).

Com efeito, como a Psicologia pode ser uma técnica de intervenção em vários domínios da cultura e da sociedade e, ao mesmo tempo, pretender-se autónoma, indiferente e desinteressada com relação aos critérios, valores e objetivos que norteiam tais domínios? Em que medida esta declarada neutralidade e esta pretenção totalizante não encobrem a funcionalidade da Psicologia a um projeto de poder extenso aos diferentes campos da vida humana?

Como solucionar essas perguntas ou afastar tal possibilidade sem entrar no mérito da visão do homem e da sociedade (ou 'meio') se quer propor ou rejeitar? e como enfrentar essa discussão sem o recurso à Filosofia?

A luz dessas questões, os posicionamento dos autores acima descritos aparecem marcados - no minino - por uma ingenuidade epistemológica.

\section{REFLEXÕES CRITICAS ACERCA DA PSICOLOGIA}

Nesse contexto, as contribuições dos dois psicólogos cariócas Euryalo Cannabrava e Jayme Grabois - parecem particularmente interessante e inovadoras. Com efeito, neles aparece clara a consciência da necessidade de submeter o conhecimento científico em geral e a Psicologia em particular a uma análise rigorosa e constante e de encara-los à luz das condições históricas em que se desenvolvem.

Jayme Grabois - por éxemplo questiona diretamente o mito da neutralidade científica, contrapondo-se frontalmente à visão de Nilton Campos 
precedentemente descrita: ' $\mathrm{Na}$ base de cada conhecimento há um certo número de pressupostos. Inclusive no do conhecimento científico. Admitir que o sábio se deve colocar em face dos fenômenos óu dos fatos, com completa isenção de espírito, surpreendendo as coisas em natura pura, sem prévias interpretações. Já implica um pressuposto epistemológico, a dualidade do mundo exterior e do indivíduo cognoscente... Uma descrição imparcial é inadmissível para quem quer leve em conta o aspecto relativista do conhecimento. A própria observação só se faz através de um conjunto de pressuposições, sem o qual ela nāo se realiza, embora o próprio indivíduo que observa não sabia quase sempre da sua existência. Assim é tanto na observação do senso comum, como na observação científica ou filosófica' (1934, p. 274).

Euryalo Cannabrava, em artigos publicado em 1933 na revista 'A Ordem' do circulo católico Dom Vital, propōe-se a realizar uma 'investigação crítica'das tendências da Psicologia moderna 'que não atenda aos preconceitos comuns, desrespeita as convençōes erigidas pelos especialistas e procure ver claro, classificar e abrir caminhos, com propósito de resolver problemas que interessam os fundamentos da cultura e da actividade scientifica. A crítica é sempre necessária, mas em nenhuma sciencia, como na psychologia, ela se tornará mais proveitosa, talvez porque, em nenhuma outra disciplina, os conceitos dogmáticos, as crenças e as falsas generalizações tenham tomado desenvolvimento tão amplo (idem, p. 821).

O aparecer desta consciência crítica com relação à própria área de conhecimento, entre alguns psicólogos brasileiros da década de trinta, é particularmente significativo e inovador, se considerado na perspectiva dos recentes debates acerca do status epistemológico e do back-ground histórico-social da Psicologia moderna. Ao mesmo tempo, esta consciência crítica tinha a função - naquela época assim como hoje - de alertar e resguardar os psicólogos com relação a possíveis submissões ou colaboraçōes com projetos de poder sobre o homem e a sociedade brasileira.

A situação de crise da Psicologia é reconduzida por Cannabrava a três fatores fundamentais:

1. o 'estado de anarchia terminologica', ou imprecisão do vocabulário,

2. a falta de uniformidade metodológica,

3. a aplicação acrítica de teorias e técnicas psicológicas imposta pelas necessidades de ordem social, aplicação que torna Psicologia um instrumento de dominação utilizado por grupos de poder. 
Essa última observação é particularmente interessante considerando a enfase pragmátista que caracterizava a postura de vários psicólogos brasileiros da época, como já foi exposto.

'Concordo que as necessidades de ordem social sejam imperiosas, escreve Cannabrava - sobretudo as que decorrem das profissōes liberaes, da medicina, de direito e do trabalho organizado, mas elas não devem impor à psychologia aplicada um critério de elasticidade que exceda os recursos dessa sciencia na sua forma actual... Não me parece recomendável que o progresso das aplicações em psychologia seja maior do que o da própria sciencia que se aplica' (idem, p. 824).

As primeiras duas causas de crise da Psicologia dependem de fatores internos a essa ciência, a terceira causa é devida a 'fatores externos, de ordem social, que penetram, cada vez mais, no domínio da psychologia’ (idem, p. 825).

Nesse ponto, Cannabrava pergunta-se de que forma enfrentar a crise e, acatando uma sugestão de K. Buhler, apela - como recurso eficaz para a crítica dos princípios psicológicos desenvolvida segundo critérios, métodos e diretrizes próprios da Epistemologia.

Nesse ponto, o autor define os objetivos de uma Epistemologia da Psicologia: estudo dos fundamentos apriorísticos da disciplina, a saber dos 'pontos de partida do investigador para chegar ao domínio dos conceitos da sua sciencia' (idem, p. 826); estudo da natureza e extensão das hipóteses formuladas pelo investigador, verificando 'se elas abrangem o número necessário de factos ou se ficou à margem algum resíduo que as possa legitimamente invalidar' (idem, p. 826) e verificando se as mesmas satisfazem os requisitos lógicos necessários.

Cannabrava considera o primeiro objetivo como especialmente importante, pois a legitimidade de uma determinada hipótese só pode ser justificada conhecendo os princípios teóricos básicos que a norteiam. A falta de crítica de tais fundamentos é uma das causas maiores de desvios e erros em Psicologia.

Para exemplificar este juízo, Cannabrava cita o caso da Pedagogia onde 'frequentemente, se lançam mão de resultados práticos sem indagar se as hypotheses theoricas, em que se baseam, se justificam ou nāo perante a crítica' (idem p. 826). Assim, por exemplo, o sistema educacional proposto por Dewey é 
completo e eficaz mas não pode ser utilizado dispensando-se o conhecimento da teoria instrumentalista que o fundamenta.

Outro caso, é a teoria beháviorista da aprendizagem por ensaios e erros baseada no postulado evolucionista da adpatação do organismo ao ambiente. Contrapondo-se à visão de Radecki que considera o problema da classificação das funçōes psíquicas como meramente metodológico. Cannabrava afirma que toda classificação de funçōes 'se basea em suposições theoricas adaptadas muitas vezes inconscientemente pelo classificador' (idem, p. 829).

Assumir um método na Psicologia é fruto de uma opção cultural. Retomando um estudo crítico de Windelband e Richert, Cannabrava afirma que a Psicologia pode ser encarada como ciência natural - sendo essa a tendência maioritária dos psicólogos a ele contemporâneos - ou como ciência cultural, ou seja de natureza histórico-social. Registra-se algumas tendências nessa segunda direção, por exemplo no pensamento do próprio Freud, que recorre muitas vezes a fatores de ordem cultural, renunciando às categorias propriamente biológicas. Uma exigência muito forte a favor da segunda orientação é a necessidade de interpretar o mundo psíquico à luz de conceitos como valor, sentido, finalidade, que não cabem numa explicação de tipo naturalista. A introdução dessas categorias leva a uma visão dos fenômenos psíquicos como totalidades, pois sentido, valor, fim, somente são identificáveis na relação com o todo. Embora o autor pareça simpatizar com essa doutrina - da qual cita entre os ilustres representantes Dilthey, Stern e Spranger, não deixa de apontar seu ponto fraco: 'Acredito que o seu principal defeito seja o de ter definido bem o objetivo que pretende alcançar mas, ao mesmo tempo, não nos oferecer depurados pela crítica, os methodos que nos poderiam levar até lá' (idem, p. 835).

Além disso, é excluido de uma visão da Psicologia como ciência cultural o estudo dos animais e das crianças, domínios de conhecimento em si muito fecundos.

Dessa forma, no estado atual das coisas, na Psicologia só parecem possíveis opções radicais e unívocas - o que implica na renuncia de temas de investigação relevantes para dedicar-se a aspectos isolados, na adoção de planos unilaterais de trabalho, no desprezo de material empírico interessante. De qualquer forma, a ótica da Psicologia como ciência cultural parece mais oportuna e razoável por respeitar a extensão e a peculiaridade do objeto, pois 'Que importam os fundamentos biológicos se não nos fazem penetrar nos aspectos do psychismo mais ligados a vida social? Se o que interessa no homem são as suas predileções e atitudes políticas, estheticas, moraes e jurídicas, nada nos impede 
de procurar uma technica que facilite esse conhecimento, ainda que seja necessária a renovação completa dos conceitos scientificos ou philosophicos' (idem, p. 837).

A proposta de Cannabrava é, então, a de que a Psicologia busque ampliar seus princípios, suas hipóteses e métodos, visando os objetos e interesses que a motivam, realizando uma constante revisão crítica de seus fundamentos e de suas aplicaçōes.

\section{CONCLUSÃO}

A atualidade dessa postura é evidente - ao considerarmos a enfase com que hoje em dia os psicólogos no Brasil e no mundo apelam para a necessidade dos estudos epistemológicos e histórico-críticos e para a oportunidade de voltar à Filosofia como instrumental de tais estudos.

É preciso levar em conta a existência de tal debate na história da cultura brasileira, pois há várias décadas alguns pesquisadores já se entretinham com problemáticas semelhantes. A atitude crítica nasce também de uma memória e só pode ser fecunda quando reconhece suas raízes e seus interesses, em suma, sua identidade.

A imagem de uma consciência crítica absoluta, desligada de uma história, de uma cultura, de interesses humanos, é uma utopia fruto do racionalismo iluminista que cada vez mais revela sua inconsistência, ou melhor o fato de ser funcional às formas de poder totalitário. Hoje a exigência de que os psicólogos brasileiros retomem sua própria história parece uma entre as condições fundamentais para que a Psicologia neste país possa realmente contribuir ao conhecimento da verdade sobre o homem e à realização de sua justa dignidade.

\section{REFERÊNCIAS BIBLIOGRAFICAS}

AlCÂNTARA, Pedro - Da Psychologia Experimental. 'Revista de Medicina' São Paulo, a. 8, 1024, n. 32-33, vol. 6, pp. 1-4. 
BARRETO, Luis Pereira - As três Filosofias e outras obras filosóficas, 1874, São Paulo, Editora da Universidade de São Paulo-Grijalbo, 1967, 317 p.

CAMPOS, Nilton - Os fundamentos positivos da Psicologia moderna, 'Boletim da Secretaria Geral de Saúde e Assistência’, Rio de Janeiro, a. 1, 1935, n. 3, pp. 5-10.

CAMPOS, Nilton - Aspectos da Psicologia, 'Boletim da Assistência Municipal', Rio de Janeiro, 1935, pp. 223-226.

CAMPOS, Nilton - As acquisiçōes da moderna Psychologia, 'Boletim da Secretaria Geral de Saúde e Assistência', Rio de Janeiro, a. 3, 1937, n. 6 pp. 63-67.

CANNABRAVA, Euryalo - Será a Psychologia Sciencia Natural ou Cultural?, Rio de Janeiro, ‘A Ordem', 1933, pp. 821-837.

GRABOIS, Jayme - A margem da Psicologia, 'Revista da Universidade do Rio de Janeiro, a. 2, 1934, n. 4-5, p. 273-278.

MEDEIROS, Maurício - A questão dos Methodos em Psicologia 'Arquivos Brasileiros de Psychiatria, Neurologia e Medicina Legal', Rio de Janeiro, a. 4, 1908, n. 1-2.

RADECKI, Waclaw - Problemas de Psychologia contemporanea, 'Sciencia Médica', Rio de Janeiro, a. 2, 1924, n. 1-12, pp. 275-283.

RADECKI, Waclaw - Methodos da Psychologia contemporanea, 'Sciencia Médica', Rio de Janeiro, a. 2, 1924, n. 1-12, pp. 504-531.

RIBEIRO, Carlos - Psicologia: Sua definição, seu objeto e suas divisões, através de multiplas divergências, Salvador, 'Arquivos do Instituto Nina Rodrigues', 1933-1934, pp. 321-334.

VELOSO, Galba - Tendências da Psicologia contemporânea, 'Arquivos de Neurologia e Psyquiatria', Belo Horizonte, v. 2, 1940, n. 2, pp. 5-16. 
This paper describes some significant aspects of the discussion about the models of scientific Psychology present in some articles published in Brazilian scientific journals at the beginning of this century.

In these journals, physicians, philosophers and psychologista discuss the objects, methods, goals and usefulness of scientific Psychology, considering the development of the most relevant theoretical proposals such as Psychoanalysis, Behaviorism, and Gestalt Theory and relating to the challenges in problems of the Brazilian social-cultural reality.

Psychology as a science is discussed within the context of more general models of science. 
